\title{
Determinants of first and second trimester induced abortion - results from a cross-sectional study taken place 7 years after abortion law revisions in Ethiopia
}

Kristine Ivalu Bonnen ${ }^{1}$, Dereje Negussie Tuijje ${ }^{2}$ and Vibeke Rasch ${ }^{1 *}$

\begin{abstract}
Background: In 2005 Ethiopia took the important step to protect women's reproductive health by liberalizing the abortion law. As a result women were given access to safe pregnancy termination in first and second trimester. This study aims to describe socio-economic characteristics and contraceptive experience among women seeking abortion in Jimma, Ethiopia and to describe determinants of second trimester abortion.

Methods: A cross-sectional study conducted October 2011 - April 2012 in Jimma Town, Ethiopia among women having safely induced abortion and women having unsafely induced abortion. In all 808 safe abortion cases and 21 unsafe abortion cases were included in the study. Of the 829 abortions, 729 were first trimester and 100 were second trimester abortions. Bivariate and multivariate logistic regressions were used to determine risk factors associated with second trimester abortion. The associations are presented as odds ratios (OR) with 95\% confidential intervals. Age stratified analyses of contraceptive experience among women with first and second trimester abortions are also presented.

Results: Socio-economic characteristics associated with increased ORs of second trimester abortion were: age $<19$ years, being single, widowed or divorced, attending school, being unemployment, being nullipara or para 3+, and having low education. The contraceptive prevalence rate varied across age groups and was particularly low among young girls and young women experiencing second trimester abortion where only $15 \%$ and $19 \%$ stated they had ever used contraception.

Conclusion: Young age, poor education and the prospect of single parenthood were associated with second trimester abortion. Young girls and young women were using contraception comparatively less often than older women. To ensure women full right to control their fertility in the setting studied, modern contraception should be made available, accessible and affordable for all women, regardless of age.
\end{abstract}

Keywords: First trimester abortion, Second trimester abortion, Unsafe abortion, Contraception, Ethiopia

\footnotetext{
* Correspondence: vrasch@health.sdu.dk

'Department of Obstetrics and Gynaecology, Odense University Hospital,

Odense, Denmark

Full list of author information is available at the end of the article
} 


\section{Background}

In 2008, an estimated $92 \%$ of African women of childbearing age lived in countries with restrictive abortion laws [1]. Since 1997, eight African countries have changed their abortion laws reducing the restrictions (Benin, Chad, Ethiopia, Guinea, Mali, Niger, Swaziland and Togo) [2]. The most liberal abortion laws in Africa are found in Cape Verde and South Africa where pregnancy termination is allowed without restriction as to reason and Zambia which permits abortion on socioeconomic grounds. In South Africa the abortion law was liberalized in 1997 and a 91\% reduction in the annual number of abortion-related deaths were observed between 1994 and $2000[3,4]$. However, seventeen years after South Africa adopted one of the world's most progressive abortion laws, women's access to safe services is becoming more difficult and unsafe abortion appears to be on the rise [5]. In 2005, Ethiopia took the important step to protect women's reproductive health by liberalizing the abortion law from 1955, which only permitted abortion to save the pregnant woman from grave and permanent danger to life. Termination of pregnancy is now also permitted where continuation of the pregnancy or birth endangers the health or life of the woman or the child, in cases of fetal impairment, if the woman has physical or mental disabilities or is a minor who is not physically or psychologically prepared to raise a child, or where pregnancy is a result of rape or incest. Under these circumstances abortion can legally be induced up to 28 weeks of gestational age.

Unwanted pregnancy is a present problem in Ethiopia as illustrated in a national quantitative study of abortion incidence where it was estimated that out of 4 million pregnancies, $42 \%$ were unwanted leading to 382,000 induced abortions [6]. The newly implemented abortion law enables women, who experience an unwanted pregnancy, to have a safe first or second trimester abortion. Studies have described the availability and quality of safe abortion service in Ethiopia after the abortion law reform. The findings show that in some areas safe abortion care service fell far short of the recommended levels [7] whereas other areas have experienced an increase in availability of safe abortion care service [8] and a corresponding decrease in treatment of incomplete abortion [9].

Abortion history and contraceptive use after the abortion law reform have been described in studies focusing on female students. According to these studies high abortion rates and low contraceptive prevalence rates prevail [10-12]. However, female students are a highly selected group of young individuals and to get a more nuanced picture of the abortion situation in Ethiopia there seems to be a need of a more general description of women who are seeking abortion. Further, since second trimester abortion may be associated with greater distress and higher rates of morbidity and mortality [13], attention should be given to this particular group of women. Against this background the present study aims to describe socio-economic characteristics and contraceptive use among women seeking first and second trimester abortion in Jimma Town and describe risk factors associated with second trimester abortion. Such information may help inform the Ethiopian family planning programme to attune their service to better reach women at risk of abortion and more specifically women at risk of second trimester abortion.

\section{Methods}

\section{Study setting}

Jimma Town has a population of 120,960 people and is the capital town of Jimma Zone which has a population of 2,486,155 people [14]. In 2011, a total of 4634 first trimester and 195 second trimester abortions were according to available registers performed in Jimma Town.

The present study was conducted in four health facilities in Jimma Town: Jimma Health Centre, Marie Stopes International Ethiopia, Family Guidance Association of Ethiopia and Jimma University Specialized Hospital.

\section{Study population}

During the period Oct 2011-April 2012 women having first and second trimester abortion and women admitted with complications after an unsafe abortion were invited to participate in the study.

First trimester abortion: Women were recruited from three health facilities in Jimma town that offered safe abortion in first trimester (Jimma Health Centre, Marie Stopes International Ethiopia, Family Guidance Association of Ethiopia). Data were collected for 3 months at each health facility. Out of 842 admitted women, 723 were eligible for interview and 718 (85\% of admitted) accepted to participate in the study (Figure 1).

Second trimester abortion: Women were recruited at Jimma University Specialized Hospital, the only health facility in Jimma town which offered second trimester abortion. Out of 112 admitted women, 94 were eligible for interview, and 90 (80\% of admitted) accepted to participate in the study.

Unsafe abortion: Women admitted with incomplete abortion at Jimma University Specialized Hospital underwent an empathic interview to determine if the incomplete abortion was a result of an unsafely induced abortion. The interviews were conducted as a confidential in-depth dialogue without any questionnaire or notes. When the interviewer felt she had gotten trustworthy information as to whether the woman had undergone an unsafe induced abortion, the informant was asked permission to record the obtained information in a structured 


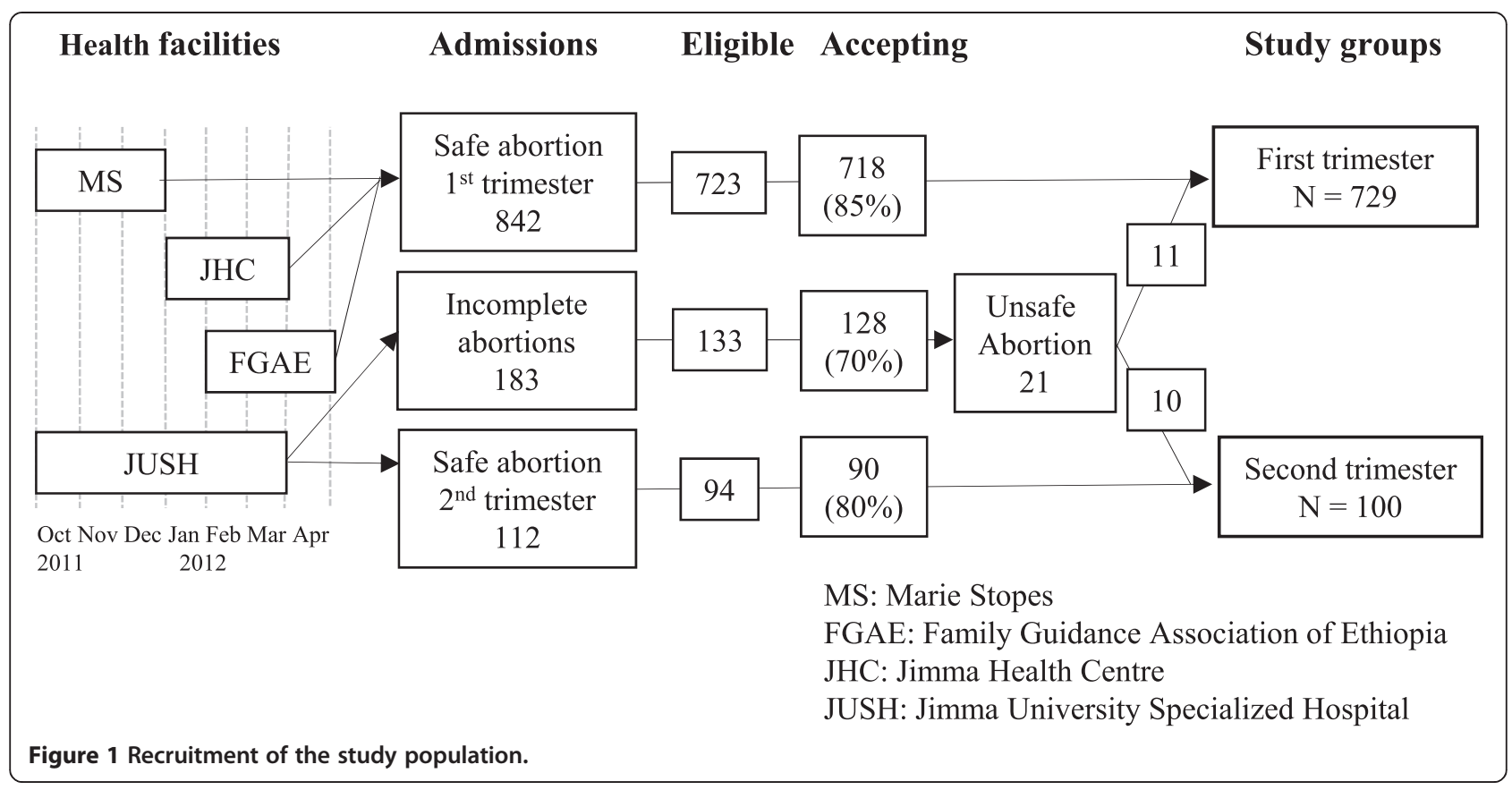

questionnaire. We have previously with success used this approach to identify women with unsafe abortion in Tanzania [15-17]. In all 183 women were admitted with incomplete abortion, 133 of these women were eligible for interview, the remaining had been discharged before they could be approached. Out of 133 eligible women, 128 (70\% of the admitted) accepted participation. In all 21 (16\%) women stated they were admitted due to complications after either a legal abortion $(n=11)$ or an illegal abortion $(\mathrm{n}=10)$ (Figure 1$)$.

In sum, 808 women with safely induced abortions were included in the study together with 21 women who had experienced an unsafely induced abortion. The small number of unsafe abortions did not allow independent analysis. Of the 829 abortion cases, 729 were performed in first trimester and 100 in second trimesters (Figure 1).

\section{Variables}

A structured questionnaire was used to obtain information on socio-economic characteristics and contraceptive use. Socio-economic variables relating to induced abortion included age ( $<19$ years, 20-24 years, $25+$ years) marital status (single, married, widowed/divorced), education level (primary school or less, secondary school or above), occupation (housewife, employed, unemployed, attending school, other occupation), place of residence (Jimma Town, Jimma Zone, other) and parity (nullipara, para I-II, para III+). To explore whether women having induced abortion had previous experience using contraception and to what extend the unintended pregnancy was a result of contraceptive failure the following variables were included; ever use of contraception (condom or modern contraception such as contraceptive pill, injection, implant or IUD), and use of contraception in relation to the intercourse where conception most likely happened.

\section{Statistical analysis}

Data were double entered in EpiData Entry 3.1 and exported to the statistical software package Stata Release 12.1 (Stata Corp. College Station, TX) for statistical analysis. The profiles of women having abortion are presented as frequencies. First and second trimester induced abortion were compared using first trimester abortions as the reference group. The associations are presented as odds ratio (OR) with 95\% confidence intervals (CI). Socioeconomic variables were controlled for confounding by logistic regression analysis, including risk factors from the bivariate analysis with P-values of $<0.05$ (age, marital status, education, place of residence, parity). Since education and occupation are closely related variable, only educational level was included in the logistic regression analysis. The multivariate analysis was repeated for women with residence in Jimma Town in order to control for the effect of place of residence.

\section{Ethics}

The women were explained the purpose of the study and were assured confidentiality. Written consent was obtained from all women accepting participation in the study. Ethical clearance was obtained from Jimma University Ethical Review Committee of the College of Public Health and Medical Science. 


\section{Results}

Socio-economical profile, women having first and second trimester abortion

The median age was 21 years for women having first trimester abortion and 18 years for those having second trimester abortion (Table 1). Women aged 20-24 years represented $46 \%$ of women obtaining abortion in first trimester. Adolescents ( $<19$ years) represented 56\% of those having abortion in second trimester. Single women accounted for $48 \%$ of the first trimester abortions and $80 \%$ of the second trimester abortions. Women who had education at secondary school level or above represented $68 \%$ of women having abortion in first trimester, whereas they only represented $32 \%$ of those having abortion in second trimester. Girls and young women attending school accounted for $42 \%$ of the first trimester abortions and $57 \%$ of the second trimester abortions. Jimma Town was the place of residence for $64 \%$ of women having first trimester abortion and for $41 \%$ of those experiencing second trimester abortion. Women who came from outside Jimma Zone accounted for $4 \%$ of women having first trimester abortion and 17\% of women having second trimester abortion. Women who had not previously given birth represented $66 \%$ of those experiencing a first trimester abortion and $84 \%$ of the women experiencing a second trimester abortion.

\section{Risk factors associated with second trimester abortion}

Multivariate analysis was used to ascertain the independent effect of each socio-economic variable on the outcome, second trimester abortion, after controlling for confounders. The multivariate analysis showed that the

Table 1 Socio-economic characteristics of women with first and second trimester induced abortion

\begin{tabular}{|c|c|c|c|c|}
\hline & First trimester abortion & Second trimester abortion & $\begin{array}{l}\text { Second trimester vs } \\
\text { first trimester abortion }\end{array}$ & $\begin{array}{l}\text { Second trimester vs } \\
\text { first trimester abortion }\end{array}$ \\
\hline & $N=729 \%$ & $N=100 \%$ & OR $(95 \% \mathrm{Cl})$ & Adjusted* OR (95\% Cl) \\
\hline \multicolumn{5}{|l|}{ Age } \\
\hline Median (rang) & $21(14-42)$ & $18(14-35)$ & & \\
\hline$<19$ years & 191/729 26.2 & $55 / 9955.6$ & $3.77(1.92-7.39)$ & $2.64(1.23-5.68)$ \\
\hline 20-24 years & $334 / 72945.8$ & 27/99 27.3 & $1.06(0.52-2.14)$ & $1.20(0.57-2.55)$ \\
\hline $25+$ years & $204 / 72928.0$ & 17/99 17.2 & 1.00 & 1.00 \\
\hline \multicolumn{5}{|l|}{ Marital status } \\
\hline Single & $345 / 72647.5$ & $80 / 10080.0$ & $6.90(3.62-13.1)$ & $6.55(3.02-14.2)$ \\
\hline Married & $357 / 72649.2$ & $12 / 1002.0$ & 1.00 & 1.00 \\
\hline Widowed/Divorced & 24/726 3.3 & $8 / 1008.0$ & $9.92(3.56-27.6)$ & $7.31(2.50-21.4)$ \\
\hline \multicolumn{5}{|l|}{ Education } \\
\hline$<$ sec school & 233/727 32.0 & $67 / 9967.7$ & $4.44(2.78-7.19)$ & $6.07(3.66-10.1)$ \\
\hline Sec school+ & $494 / 72768.0$ & $32 / 9932.3$ & 1.0 & 1.00 \\
\hline \multicolumn{5}{|l|}{ Occupation } \\
\hline Housewife & 145/727 19.9 & $1 / 991.01$ & $0.10(0.002-0.71) \neq$ & $0.07(0.01-0.56)$ \\
\hline Employed & 197/727 27.1 & 13/99 13.1 & 1.00 & 1.00 \\
\hline Unemployed & 10/727 1.4 & 9/99 9.1 & $13.6(4.31-43.2)$ & $10.1(2.92-35.0)$ \\
\hline Attending school & $305 / 72742.0$ & $56 / 9956.6$ & $2.78(1.47-5.26)$ & $2.35(1.10-5.00)$ \\
\hline Other & 70/727 9.6 & 20/99 20.2 & $4.33(1.99-9.37)$ & $1.85(0.79-4.32)$ \\
\hline \multicolumn{5}{|l|}{ Place of residence } \\
\hline Jimma Town & $463 / 72763.7$ & $41 / 10041.0$ & 1.00 & 1.00 \\
\hline Jimma Zone & 235/727 32.3 & $42 / 10042.0$ & $2.02(1.27-3.20)$ & $1.71(1.04-2.81)$ \\
\hline Other & $9 / 7274.0$ & 17/100 17.0 & $6.62(3.28-13.4)$ & $9.13(4.20-19.8)$ \\
\hline \multicolumn{5}{|l|}{ Parity } \\
\hline 0 & $481 / 72966.3$ & $84 / 10084.0$ & $4.30(2.03-9.13)$ & $2.55(1.17-5.56)$ \\
\hline $1-2$ & 197/729 27.1 & 8/100 8.0 & 1.00 & 1.00 \\
\hline $3+$ & $48 / 7296.6$ & $8 / 1008.0$ & $4.10(1.44-11.7)$ & $7.09(2.41-20.9)$ \\
\hline
\end{tabular}

Significant results are marked in Bold.

fFisher's exact (all other: chi2).

*Adjusted for; Age, Marital status, Education, Place of residence, Parity.

Missing values are not shown in the columns, and therefore column sum do not add up with total in top row. 
OR of having abortion in second trimester relative to having abortion in first trimester, were two times greater for women aged 19 years or younger compared to women aged $25+$ years $(\mathrm{OR}=2.64 \% \mathrm{CI}$ : $1.23-5.68)$ (Table 1). The OR of having the abortion in second trimester was six times higher for single women in comparison with married women (OR $=6.55 \% \mathrm{CI}$ : 3.02-14.2). Similarly, widowed or divorced women had seven times increased OR of having abortion in second trimester relative to having abortion in first trimester $(\mathrm{OR}=7.31$; 95\% CI: 2.50-21.4). The odds of having a second trimester abortion were six times greater for women having education on primary school level or below compared to women who had education at secondary school level or above (OR: 6.07; 95\% CI: 3.66-10.1). Occupational situation was associated with second trimester abortion. Women or girls who were still attending school had in comparison with employed women, a twice increased OR of having second trimester abortion $(\mathrm{OR}=2.35$; $95 \%$ CI: 1.10-5.00). To be a housewife seemed to be a protective factor for having second trimester abortion, $(\mathrm{OR}=0.07 ; 95 \% \mathrm{CI}: 0.01-0.56)$. Unemployment was found to be associated with a ten time increased OR for second trimester abortion $(\mathrm{OR}=10.1$; $95 \% \mathrm{CI}: 2.92-35.0)$. For women with residence in Jimma Zone the odds of having second trimester abortion relative to having first trimester abortion, were nearly twice that of women with residence in Jimma Town (OR $=1.7$; 95\% CI: 1.04-2.81). The odds of having second trimester abortion were nine times greater for women with residence outside Jimma Zone compared with women with residence in Jimma Town $(\mathrm{OR}=9.13$, 95\% CI; 4.20-19.8). Finally, a significant association between parity and second trimester abortion was found. Women who were nullipara had in comparison to women who were para I-II, a more than twice increased OR of having second trimester abortion relative to having abortion in first trimester $(\mathrm{OR}=2.55 ; 95 \% \mathrm{CI}$ 1.17-5.56). Women who were para III or more had a seven times greater OR of having second trimester abortion (OR: 7.09; 95\% CI: 2.41-20.9).

The multivariate analysis was repeated for women with residence in Jimma Town only, and showed that for this group marital status and education level were associated with second trimester abortion. Among women with residence in Jimma Town the OR of having second trimester abortion relatively to having first trimester abortion were five times greater for single women compared with married women (OR: 5.07; 95\% CI: 1.71-15.0) (Table 2). For the same group the OR of having second trimester abortion were four times greater for women having education on primary school level or below compared to women having education at secondary school level or above (OR: 4.08; 95\% CI: 2.00-8.33).

\section{Contraception}

Ever use of modern contraception was reported by $67 \%$ of the women having first trimester induced abortion and $21 \%$ of the women having second trimester induced abortion (Table 3). Ever use of contraception by age groups is presented in Figure 2. The frequency in contraceptive use increased by age among both women having first and second trimester abortion, however, across all age groups the proportion of women who stated they had ever used contraception was comparatively lower among second trimester abortion women. In the age group $<19$ years, $44 \%$ of the girls having first trimester abortion had ever used contraception whereas the same applied for only $15 \%$ of the girls having second trimester abortion. Among young women aged $20-24,70 \%$ of first trimester and $19 \%$ of second trimester abortion women had ever used contraception. Among women aged $25+, 85 \%$ of first trimester and $47 \%$ of second trimester abortion women had ever used contraception. In relation to the intercourse where conception most likely happened a similar picture was found (Figure 3 ). In the age group $<19$ years, $16 \%$ of the girls having first trimester abortion and 5\% of the girls having second trimester abortion stated they had used contraception in relation to the intercourse where they conceived. Among young women aged 2024 , the same applied for $28 \%$ having first trimester and $7 \%$ having second trimester abortion whereas $37 \%$ and $12 \%$ of women aged $25+$ with first trimester and second trimester abortion stated the same. Hence, the proportion of women, who stated contraceptive use at the intercourse where they most likely conceived, increased by age among both groups of abortion women but across all age groups the prevalence rates were significantly lower among women having second trimester abortion.

\section{Discussion}

This study describes risk factors for second trimester abortion in a setting where safe abortion service has recently been made available by law. Low level of education and the prospect of single parenthood were strong predictors for second trimester abortion. The contraceptive prevalence rate varied across age groups and was particularly low among young girls and young women experiencing second trimester abortion.

Young girls aged 19 or below were overrepresented in this study where they comprised $26 \%$ of first trimester abortion and $56 \%$ of second trimester abortion women, respectively. In comparison, a study covering the period from 1990 to 2008 estimated the proportion of abortions among 15-19 year olds in Africa to be 22\%, a figure which makes Africa the world region with the highest abortion rate among young girls [18]. When focusing on the age group $20-24$ years, $46 \%$ among women having 
Table 2 Socio-economic characteristics of women with residence in Jimma Town having first and second trimester induced abortion

\begin{tabular}{|c|c|c|c|c|}
\hline & First trimester abortion & Second trimester abortion & $\begin{array}{l}\text { Second trimester vs } \\
\text { first trimester abortion }\end{array}$ & $\begin{array}{l}\text { Second trimester vs } \\
\text { first trimester abortion }\end{array}$ \\
\hline & $\mathrm{N}=463 \%$ & $\mathrm{~N}=41 \%$ & OR $(95 \% \mathrm{Cl})$ & Adjusted* OR $(95 \% \mathrm{Cl})$ \\
\hline \multicolumn{5}{|l|}{ Age } \\
\hline Median (rang) & $21(14-38)$ & $18(14-27)$ & & \\
\hline$<19$ years & $119 / 46325.7$ & $25 / 4161.0$ & $6.93(2.27-21.2)$ & $2.88(0.82-10.2)$ \\
\hline 20-24 years & $212 / 46345.8$ & $12 / 4129.3$ & $1.87(0.59-5.93)$ & $1.30(0.36-4.62)$ \\
\hline $25+$ years & $132 / 46328.5$ & $4 / 419.8$ & 1.00 & 1.00 \\
\hline \multicolumn{5}{|l|}{ Marital status } \\
\hline Single & $221 / 46148.0$ & $35 / 4185.4$ & $7.13(2.68-18.9)$ & $5.07(1.71-15.0)$ \\
\hline Married & $225 / 46148.8$ & $5 / 4112.2$ & 1.00 & 1.00 \\
\hline Widowed/Divorced & $15 / 4613.5$ & $1 / 412.4$ & $3.00(0.33-27.59)$ & $2.42(0.23-25.0)$ \\
\hline \multicolumn{5}{|l|}{ Education } \\
\hline$<$ sec school & 139/462 30.1 & $24 / 4158.5$ & $3.28(1.63-6.71)$ & $4.08(2.00-8.33)$ \\
\hline Sec schoolt+ & $323 / 46269.9$ & $17 / 4141.5$ & 1.00 & 1.00 \\
\hline \multicolumn{5}{|l|}{ Occupation } \\
\hline Housewife & $80 / 46317.3$ & $1 / 412.4$ & $0.20(0.004-1.56) \neq$ & $0.28(0.03-2.58)$ \\
\hline Employed & $129 / 46327.9$ & $8 / 4119.5$ & 1.00 & 1.00 \\
\hline Unemployed & 5/463 1.1 & $3 / 417.3$ & $9.68(1.82-51.3)$ & $4.02(0.61-26.3)$ \\
\hline Attending school & $201 / 46343.4$ & $25 / 4161.0$ & $2.00(1.87-4.60)$ & $1.22(0.45-3.30)$ \\
\hline Other & $48 / 46310.4$ & $4 / 419.8$ & $1.34(0.38-4.69)$ & $0.50(0.13-1.96)$ \\
\hline \multicolumn{5}{|l|}{ Parity } \\
\hline 0 & $309 / 46367.0$ & $37 / 4190.3$ & $5.07(1.56-26.1) \neq$ & $2.16(0.53-8.78)$ \\
\hline $1-2$ & $127 / 46327.6$ & $3 / 417.3$ & 1.00 & 1.00 \\
\hline $3+$ & 25/463 5.4 & $1 / 412.4$ & $1.69(0.31-22.0) \neq$ & $2.99(0.27-33.6)$ \\
\hline
\end{tabular}

Significant results are marked in Bold.

FFisher's exact (all other: chi2).

*Adjusted for; Age, Marital status, Education, Parity.

Missing values are not shown in the columns, and therefore column sum do not add up with total in top row.

first trimester abortion and 27\% among women having second trimester abortion belonged to this age group. In the aforementioned study, women aged 20-24 comprised $29 \%$ of all abortion in Africa. Hence, young girls and young women account for a disproportionate share of abortions in our study, a notably finding which likely reflects that young unmarried Ethiopian women, due to fear of the stigma attached to non-marital sexual activity, are having particular difficulties in avoiding unintended pregnancies. This fear may inhibit them from obtaining contraceptive services and from using methods correctly and consistently $[18,19]$.

Single women were overrepresented among both first and second trimester abortion cases and in the comparative analysis the prospect of single parenthood was strongly associated with second trimester abortion. A tendency of delay in women's age at marriage has been suggested to result in increased sexual activity among unmarried women, raising their risk of unintended pregnancy $[6,20,21]$. Single women are susceptible to induced abortion because of the stigmatizing and economic conditions that makes single motherhood highly disadvantaged. The statistics showing an almost universal childlessness among unmarried women in Ethiopia suggest the absence of any place in the society for unmarried women with children [20].

Women who had attended secondary school accounted for two-third of women having first trimester abortion whereas only one-third among women having second trimester had attended secondary school. Jimma is a university town and has a high density of students enrolled in higher education programs. This could be part of the explanation why educated women seem to be overrepresented among first trimester abortion cases. On the other hand, our findings may also reflect that educated women may be considered a group of first movers, using their rights to access safe abortion [22]. A study from North-western Ethiopia has similarly found that the 
Table 3 Contraception among women with first and second trimester abortion

\begin{tabular}{lll}
\hline & $\begin{array}{l}\text { First trimester } \\
\text { abortion } \\
\mathbf{N}=\mathbf{7 2 9} \%\end{array}$ & $\begin{array}{l}\text { Second trimester } \\
\text { abortion } \\
\mathbf{N}=100 \%\end{array}$ \\
\hline $\begin{array}{lll}\text { Ever used contraceptives } \\
\text { Yes }\end{array}$ & $\begin{array}{l}\text { 487/724 67.3 } \\
\text { No }\end{array}$ & $21 / 9921.2$ \\
Ever used condom & & $78 / 9978.8$ \\
$\quad$ Yes & $161 / 71622.5$ & $6 / 996.1$ \\
$\quad$ No & $555 / 71677.5$ & $93 / 9993.9$ \\
$\begin{array}{l}\text { Ever used hormonal } \\
\text { contraceptives }\end{array}$ & \\
$\quad \begin{array}{l}\text { Yes } \\
\text { No }\end{array}$ & $406 / 72855.8$ & $19 / 10019.0$ \\
Contraceptives when conceived & $322 / 72844.2$ & $81 / 10081.0$ \\
$\quad$ Yes & & \\
$\quad$ No & $199 / 72527.5$ & $7 / 1007.0$ \\
\hline
\end{tabular}

Missing values are not shown in the columns, and therefore column sum do not add up with total in top row.

number of women experiencing induced abortion increased with higher educational level [23]. Further, a recent study among Ethiopian female university and college students found that $32.1 \%$ of the students were familiar with the liberalization of the abortion law and women who were aware of the law were more likely to have experienced an induced abortion [11]. Our findings are further in line with a Nepalese study showing that in 2006, four years after legislation of the Nepalese abortion law, women's knowledge of availability of legal abortion and providers increased with their educational level. The findings of the present study are, however, in contrast to a South African study which found no association between educational level and knowledge of the abortion legislation [24]. In the comparative analyses between women having first and second trimester abortion, women who had not

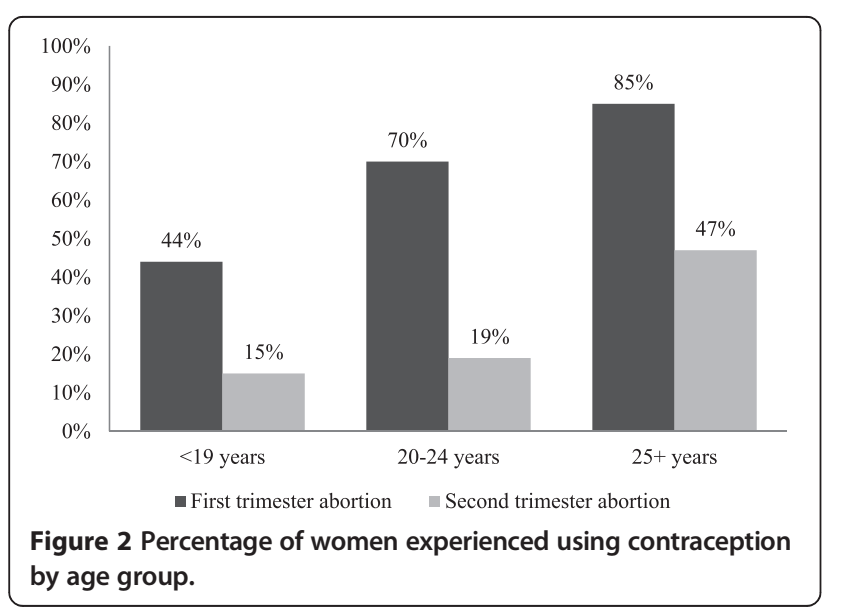

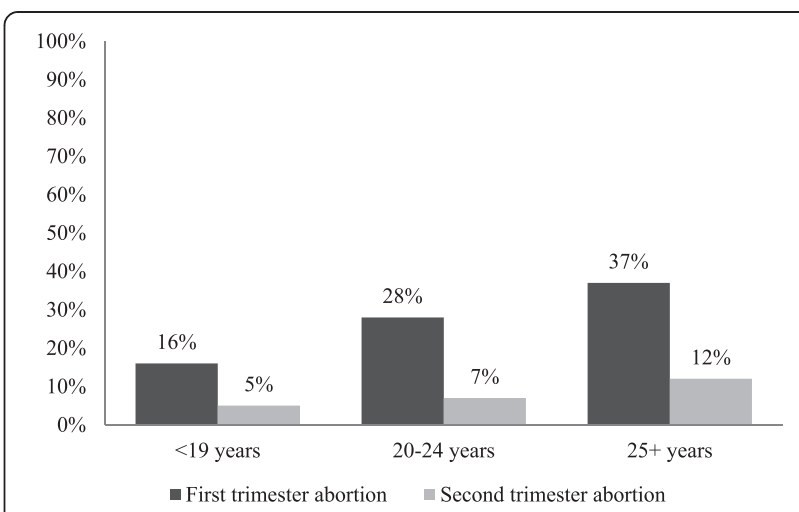

Figure 3 Percentage of women using contraception in relation to intercourse where conceived by age group.

attended secondary school had a six times increased risk of second trimester abortion. Hence, women having second trimester abortion did not belong to the same group of educated individuals as women having first trimester abortion did. Low educational level has previously been found to be associated with second trimester abortion in studies comparing first and second trimester abortion $[25,26]$. A plausible explanation for this association could be that less-educated women tend to take longer time between suspecting pregnancy and confirming it [27].

Contraceptive experience and use of contraception in relation to the intercourse where conception most likely happened were especially low among women having second trimester abortion. The women were not asked for their motivation for having an abortion and it is possible that some women having second trimester abortion as well as first trimester abortion did not use family planning at the time of conception because they wanted to become pregnant. The contraceptive experience was in particular low among young girls aged 15-19 years, where only $44 \%$ of the girls obtaining first trimester abortion and $15 \%$ of the girls obtaining second trimester abortion stated they had ever used contraception. Our findings are in contrast to a recent Ethiopian study among women receiving post abortion care, where $67 \%$ reported to have used contraceptives at least once in their life time [28]. They are also in contrast to a study conducted among secondary school students where $86 \%$ of sexually active girls reported they had ever used contraception [12]. Furthermore, our findings are in contrast to an Ethiopian study which found that $75 \%$ of undergraduate students, who had had unprotected sexual intercourse, had ever used emergency contraception [29]. Hence, the women with second trimester abortion seem to comprise a particularly group of young and poorly educated girls who are prone not to use contraception. This poor contraceptive use may reflect that many of the girls had not attended secondary school and 
therefore not been exposed to sexual and reproductive health education. Our findings are noteworthy and point to a grave need of contraceptive counseling and service reaching all young girls, regardless of their schooling level.

The Ethiopian abortion law is the result of several years' effort by a coalition of health and women's rights advocates who have worked together to ensure women better access to safe abortion. However, a liberal abortion law in a country does not guarantee access to safe abortion services. The experience from South Africa, where abortion has been legal since 1996, illustrates how implementation of a liberal abortion law may fail if there is no support from all involved stakeholders. Despite South Africa has some of the most developed government systems for the provision of abortion care, fewer than $50 \%$ of the public-sector health facilities licensed to provide abortion care are actually providing services and the number of unsafe abortion is on the rise [5]. Against this background, the present study also attempted to assess the magnitude of unsafe abortion in Jimma Town. Only 21 unsafe abortion cases were identified, equal to $16 \%$ of all admitted abortion complications. It may be questioned whether the study succeeded in covering all unsafe abortion cases. Some women may have had an unsafe abortion but not experienced any abortion complications or may have been treated at a health facility not authorised to handling abortion complications. Additionally some women may have been reluctant in revealing having had an unsafe abortion for fear of the legal consequences. On the other hand it may be argued that safe abortion is easily accessible in Jimma town, indicated by the fact that almost five thousand safely induced abortions were performed in 2011. The service is additionally being offered at reasonable price, varying form being free of charge in public health facilities and available at modest modes cost in NGO supported health facilities. It may therefore be anticipated that women in Jimma town are benefitting from the easy access to safe abortion, a factor which may prevent them from resorting to unsafe and risky interventions.

There are two noteworthy limitations of this study: representativity and the possibility of underreporting of unsafe abortions. The study was conducted in Jimma Town which is a university city and young women who are enrolled in colleges and universities are likely overrepresented in our study. The study population can therefore not be considered a representative sample of women having induced abortion in Ethiopia. However, data were collected at both public and private health facilities in Jimma Town and it achieved a high response rate. For that reason we believe that the study population can be considered representative for women obtaining safe abortion in Jimma Town. Further, to give a thorough picture of women obtaining abortion, data were also collected among women having unsafe abortion. Women who have undergone unsafe abortion are often reluctant or unwilling to discuss their experiences for fear of the consequences and may thus be underrepresented in this study. It can be argued that the determinants obtaining safe abortion are different from the determinants of obtaining unsafe abortion and the associations should thus have been analysed independently. Unfortunately, the small number of unsafe abortions did not allow for an independent analysis of unsafe abortions.

\section{Conclusion}

Ethiopia took an important step towards addressing women's sexual and reproductive health and rights in 2005 where the country implemented a liberal abortion law. However, to ensure women full right to control their fertility, it is essential that both safe abortion and modern contraception is available, accessible and affordable for all women. Young girls and young women accounted for a disproportional share of first and especially second trimester abortions in our study and their reported contraceptive use was strikingly low. Based on these findings, we argue that there is grave need for making contraceptive information and services available to all Ethiopian women, irrespective of age.

\section{Competing interests}

The authors declare that they have no competing interests.

\section{Authors' contributions}

KIB participated in the conception, design, and implementation of the study, statistical analysis, interpretation, and drafting of manuscript. DNT and VR participated in developing the study design, the implementation, and the interpretation of the findings. All authors have read and approved the final manuscript.

\section{Acknowledgements}

The authors thank Dr Ahadu Workinch, Department of Obstetrics and Gynaecology, Jimma University Specialized Hospital, Ethiopia, for his contributions during the data collection. The study was supported by grants from NFOG (The Nordic Federation of Gynaecology and Obstetrics), DSOG (The Danish Society of Obstetrics and Gynaecology) and Danida.

\section{Author details}

1Department of Obstetrics and Gynaecology, Odense University Hospital, Odense, Denmark. '2Department of Obstetrics and Gynaecology, Jimma University Specialized Hospital, Jimma, Ethiopia.

Received: 5 May 2014 Accepted: 5 December 2014

Published online: 19 December 2014

\section{References}

1. Facts on abortion in Africa. in brief. 2012. http://www.guttmacher.org/ pubs/IB_AWW-Africa.pdf.

2. Singh S, Wulf D, Hussain R, Bankole A, Sedgh G: Abortion Worldwide: A Decade of Uneven Progress. New York; 2009.

3. Jewkes R, Brown H, Dickson-Tetteh K, Levin J, Rees H: Prevalence of morbidity associated with abortion before and after legalisation in South Africa. BMJ (Clinical Research Ed) 2002, 324(7348):1252-1253.

4. Jewkes R, Rees H: Dramatic decline in abortion mortality due to the choice on termination of pregnancy act. S Afr Med J 2005, 95(4):250. 
5. Trueman KA, Magwentshu M: Abortion in a progressive legal environment: the need for vigilance in protecting and promoting access to safe abortion services in South Africa. Am J Public Health 2013, 103(3):397-399.

6. Singh S, Fetters T, Gebreselassie H, Abdella A, Gebrehiwot Y, Kumbi S, Audam S: The estimated incidence of induced abortion in Ethiopia, 2008. Int Perspect Sex Reprod Health 2010, 36(1):16-25.

7. Abdella A, Fetters T, Benson J, Pearson E, Gebrehiwot Y, Andersen K Gebreselassie H, Tesfaye S: Meeting the need for safe abortion care in Ethiopia: results of a national assessment in 2008. Glob Public Health 2013, 8(4):417-434.

8. Otsea K, Benson J, Alemayehu T, Pearson E, Healy J: Testing the safe abortion care model in Ethiopia to monitor service availability, use, and quality. Int J Gynaecol Obstet 2011, 115(3):316-321.

9. Prata N, Bell S, Gessessew A: Comprehensive abortion care: evidence of improvements in hospital-level indicators in Tigray, Ethiopia. BMJ Open 2013, 3(7).

10. Gelaye AA, Taye KN, Mekonen T: Magnitude and risk factors of abortion among regular female students in Wolaita Sodo University, Ethiopia. BMC Womens Health 2014, 14:50.

11. Animaw W, Bogale B: Abortion in university and college female students of Arba Minch town, Ethiopia, 2011. Sex Reprod Healthc 2014, 5(1):17-22.

12. Melaku YA, Berhane Y, Kinsman J, Reda HL: Sexual and reproductive health communication and awareness of contraceptive methods among secondary school female students, northern Ethiopia: a cross-sectional study. BMC Public Health 2014, 14(1):252.

13. Dragoman M, Sheldon WR, Qureshi Z, Blum J, Winikoff B, Ganatra B: Overview of abortion cases with severe maternal outcomes in the WHO Multicountry Survey on Maternal and Newborn Health: a descriptive analysis. BJOG 2014, 121(Suppl 1):25-31.

14. Federal Democratic Republic of Ethiopia: Population Census Commission. Summary and Statistical Report of the 2007 Population and Housing Census Population Size by Age and Sex. 2008, http://ecastats.uneca.org/aicmd/ Portals/0/Cen2007_firstdraft.pdf.

15. Rasch V, Muhammad H, Urassa E, Bergstrom S: Self-reports of induced abortion: an empathetic setting can improve the quality of data. Am J Public Health 2000, 90(7):1141-1144.

16. Rasch V, Massawe S, Yambesi F, Bergstrom S: Acceptance of contraceptives among women who had an unsafe abortion in Dar es Salaam. Trop Med Int Health 2004, 9(3):399-405.

17. Rasch V, Kipingili R: Unsafe abortion in urban and rural Tanzania: method, provider and consequences. Trop Med Int Health 2009, 14(9):1128-1133.

18. Sedgh G, Bankole A, Singh S, Eilers M: Legal abortion levels and trends by woman's age at termination. Perspect Sex Reprod Health 2013, 45(1):13-22.

19. Molla M, Berhane $Y$, Lindtjorn B: Traditional values of virginity and sexual behaviour in rural Ethiopian youth: results from a cross-sectional study. BMC Public Health 2008, 8:9.

20. Sibanda A, Woubalem Z, Hogan DP, Lindstrom DP: The proximate determinants of the decline to below-replacement fertility in Addis Ababa, Ethiopia. Stud Fam Plann 2003, 34(1):1-7.

21. Okereke $\mathrm{Cl}$ : Assessing the prevalence and determinants of adolescents' unintended pregnancy and induced abortion in Owerri, Nigeria. J Biosoc Sci 2010, 42(5):619-632.

22. Thapa S, Sharma SK: Women's awareness of liberalization of abortion law and knowledge of place for obtaining services in Nepal. Asia Pac J Public Health 2012.

23. Senbeto $\mathrm{E}$, Alene $\mathrm{G}$, Abesno N, Yeneneh $\mathrm{H}$ : Prevalence and associated risk factors of Induced Abortion in northwest Ethiopia. 2005, 19(1):37-44. Ethiop J Health Dev 2005, 19(1):8.

24. Morroni C, Myer L, Tibazarwa K: Knowledge of the abortion legislation among South African women: a cross-sectional study. Reproductive Health 2006, 3:7.

25. Usta MB, Mitchell EM, Gebreselassie H, Brookman-Amissah E, Kwizera A: Who is excluded when abortion access is restricted to twelve weeks? evidence from Maputo, Mozambique. Reprod Health Matters 2008, 16(31 Suppl):14-17.

26. Drey EA, Foster DG, Jackson RA, Lee SJ, Cardenas LH, Darney PD: Risk factors associated with presenting for abortion in the second trimester. Obstet Gynecol 2006, 107(1):128-135.
27. Finer LB, Frohwirth LF, Dauphinee LA, Singh S, Moore AM: Timing of steps and reasons for delays in obtaining abortions in the United States. Contraception 2006, 74(4):334-344.

28. Tesfaye G, Hambisa MT, Semahegn A: Induced abortion and associated factors in health facilities of Guraghe Zone, southern Ethiopia. J Pregnancy 2014, 2014:295732.

29. Ahmed FA, Moussa KM, Petterson KO, Asamoah BO: Assessing knowledge, attitude, and practice of emergency contraception: a cross- sectional study among Ethiopian undergraduate female students. BMC Public Health 2012, 12:110.

\section{Submit your next manuscript to BioMed Central and take full advantage of:}

- Convenient online submission

- Thorough peer review

- No space constraints or color figure charges

- Immediate publication on acceptance

- Inclusion in PubMed, CAS, Scopus and Google Scholar

- Research which is freely available for redistribution 